\title{
Dynamic Profiling of Insulin Secretion and ATP Generation in Isolated Human and Mouse Islets Reveals Differential Glucose Sensitivity
}

\author{
Attilio Pingitore Inmaculada Ruz-Maldonado Bo Liu Guo Cai Huang \\ Pratik Choudhary Shanta J. Persaud \\ Department of Diabetes, School of Life Course Sciences, King's College London, London UK
}

\section{Key Words}

Islets of Langerhans Insulin secretion - ATP generation - Glucose transporters • Metabolic coupling • GLUT1

\begin{abstract}
Background/Aims: Rodent islets are often used for basic science research but they do not always recapitulate signalling events in human islets. This study evaluated the glucosedependent responses of human and mouse islets in terms of dynamic insulin secretion, metabolic coupling and the role of glucose transporters. Methods: Glucose-induced insulin secretion from isolated mouse and human islets was profiled by perifusion and islet ATP levels were measured by chemoluminescence assay. Glucose transporter expression was determined by qPCR and western blotting. Results: Human islets show a left-shifted glucose concentration-insulin secretion profile compared to mouse islets. These data are consistent with glucose transporter expression, with human islets expressing mainly GLUT1 and GLUT3, and GLUT2 being the predominant transporter in mouse islets. Using the GLUT1 inhibitor STF-31 we unveiled an important role for GLUT1 for differences in glucose-induced insulin secretion profiles observed between the two species. Conclusion: The high affinity of GLUT1/3 for glucose reflects the left-shifted glucose-induced insulin secretory response of human islets and the impairment of insulin secretion from human islets after STF-31 treatment indicates an important role for GLUT1 in human islet stimulus-secretion coupling. Our data provide further insight into key differences between insulin secretion regulation in mouse and human islets.
\end{abstract}

\section{Introduction}

The limited availability of human islets for research has prompted researchers to study the physiological regulation of insulin secretion using islets isolated from other mammals, mainly mice and rats. Although rodent islets are widely used as human islet surrogates
(C) 2017 The Author(s)

Published by S. Karger AG, Basel
A. Pingitore and

KARGER 
and they represent valid models to study endocrine pancreas physiology, there is evidence of differences in morphology [1], expression of cell surface receptors [2] and function [3] between mouse and human islets.

It is well established that the key coupling between increases in blood glucose levels and enhanced insulin release from islets is through glucose uptake into $\beta$-cells via the solute carrier family 2, facilitated glucose transporter proteins known as GLUTs, followed by its glycolytic and oxidative metabolism. The increased ATP/ADP ratio leads to closure of $\beta$-cell $\mathrm{K}_{\text {ATP }}$ channels, membrane depolarisation and $\mathrm{Ca}^{2+}$ influx via voltage-gated calcium channels that triggers insulin exocytosis $[4,5]$. Thus, glucose uptake and its intracellular metabolism to generate ATP and elevate $\left[\mathrm{Ca}^{2+}\right] \mathrm{i}$ represent fundamental steps for the initiation of the signalling cascade leading to insulin secretion from $\beta$-cells. Patch clamp electrophysiological analyses have indicated that human islet $\mathrm{K}_{\text {ATP }}$ channels [6] and L-type voltage-gated calcium channels [7] show similar characteristics to those identified in rodent islets. However, differences have been identified in glucose transporter expression between rodent and human islets, with preferential expression of GLUT1 and GLUT2 in human and rat islets, respectively [8-10].

The 14 GLUT family members so far identified are characterised by different affinities for glucose [11]. The high affinity GLUT1 and GLUT3 transporters have $\mathrm{K}_{\mathrm{m}}$ values of 1-4mM, which means that under normal resting plasma glucose concentrations of approximately $4 \mathrm{mM}$ in humans there should be constant glucose entry into cells expressing these transporters. On the other hand, the GLUT2 transporter has a $\mathrm{K}_{\mathrm{m}}$ of $>15 \mathrm{mM}$ and is thus a low affinity glucose transporter that is most active when plasma glucose concentrations are elevated. Given that the majority of stimulus-response coupling signal transduction cascades identified in mouse and rat islets are also observed in human islets [3, 4], the distinct GLUT expression profile [8-10] is somewhat surprising. In the current study we have quantified expression of the SLC2A/Slc2a genes encoding GLUT1, 2 and 3 in isolated human and mouse islets respectively, and also determined relative protein expression of these glucose transporters in human and mouse islets. In addition, we have explored whether the glucose-dependent ATP and insulin secretion profiles are dependent on the distinct GLUT expression.

\section{Materials and Methods}

\section{Materials}

Culture media and supplements, general laboratory chemicals: Sigma-Aldrich (Dorset, UK). Tissue culture flasks, cover slips, bicinchoninic acid (BCA) protein assay, 10\% polyacrylamide gels, NuPAGE® sample buffer, transfer buffer: Thermo Fisher Scientific (Paisley, UK). ACTB antibodies, X-ray film: Santa Cruz Biotechnologies (Middlesex, UK). GLUT1, GLUT2, GLUT3 antibodies: Abcam (Cambridge, UK). Nonfat dried milk (VWR International Ltd, Lutterworth, UK). HRP-conjugated secondary antibody, enhanced chemiluminescent (ECL) western blotting reagents, Cell Titer-Glo 3D assay: Promega (Hampshire, UK). RIPA buffer, Rainbow molecular weight markers and nitrocellulose membrane: Millipore (Watford, UK), STF-31: Calbiochem (Watford, UK). RNeasy RNA extraction kit and Quantitect qPCR primers: Qiagen (Manchester, UK). High capacity reverse transcriptase kit: Applied Biosystems (Woolston, UK)

\section{Isolation of human and mouse islets}

Human islets were isolated from the pancreases of heart beating non-diabetic organ donors (6 male, 4 female, $41.5 \pm 2.9$ years, BMI: $27.5 \pm 1.3 \mathrm{~kg} / \mathrm{m}^{2}$; Table 1) at the King's College Hospital Islet Transplantation Unit, with appropriate ethical approval (LREC 01-082) [12]. The islets were maintained in CMRL medium supplemented with $2 \%$ human albumin, $4 \mathrm{mM}$ glutamine, $2 \mathrm{mM}$ HEPES (pH 7.2-7.4), and 10mM nicotinamide at $37^{\circ} \mathrm{C}, 5 \% \mathrm{CO}_{2}$ prior to functional analyses. Male CD1 mice (8 weeks, 25-28g) were purchased from Charles River Laboratories (Margate, UK) and housed in groups of up to 6 in cages in the Biological Services Unit at King's College London. Mice were maintained on standard chow until islets were isolated by collagenase digestion of the exocrine pancreas and purified on a histopaque gradient [13]. Mouse islets were maintained at $37^{\circ} \mathrm{C}, 5 \% \mathrm{CO}_{2}$ in RPMI supplemented with $10 \%$ fetal bovine serum, $2 \mathrm{mM}$ glutamine and $100 \mathrm{U} / \mathrm{ml} / 0.1 \mathrm{mg} /$ $\mathrm{ml}$ penicillin/streptomycin. 


\section{Cellular Physiology Cell Physiol Biochem 2017;44:1352-1359 \begin{tabular}{ll|l} 
and Biochemistry Published onIIne: November 30, 2017 & $\begin{array}{l}\text { (C) } 2017 \text { The Author(s). Published by S. Karger AG, Basel } \\
\text { www.karger.com/cpb }\end{array}$ \\
\hline
\end{tabular}

\section{Quantification of GLUT mRNA expression}

Total RNA was extracted from groups of 200 isolated human or mouse islets using the Qiagen RNeasy Minikit according to the manufacturer's instructions then mRNAs were reverse-transcribed into cDNAs, which were quantified using a NanoDrop spectrophotomoter. Quantitative PCR reactions were performed on a Lightcycler 480 using $1 \mu \mathrm{g}$ of cDNA and species-specific primers for SLC2A1, 2 and 3/Slc2a1, 2 and 3, and expression levels were normalised to GAPDH/ Gapdh mRNA expression in the same samples [14].

\section{Identification of GLUT protein expression}

Groups of 200 purified human or mouse islets were lysed with radioimmunoprecipitation assay (RIPA) buffer and protein contents were quantified by the BCA method. $25 \mu \mathrm{g}$ of islet protein extracts were fractionated by denaturing SDS polyacrylamide gel electrophoresis (10\% gel, 45 minutes, $200 \mathrm{~V}$ ), transferred onto $0.2 \mu \mathrm{m}$ nitrocellulose, blocked with $5 \%$ milk for one hour at room temperature and probed overnight at $4^{\circ} \mathrm{C}$ with rabbit antibodies directed against GLUT1 (1:1, 000),

GLUT2 (1:500) or GLUT3 $(1: 1,000)$. Membranes were then incubated for $1 \mathrm{~h}$ at room temperature with anti-rabbit HRP-conjugated secondary antibody $(1: 10,000)$ and exposed to X-ray film after addition of ECL substrate. Membranes were re-probed with a mouse anti- $\beta$-actin antibody $(1: 1,000)$ and anti-mouse HRPconjugated secondary antibody $(1: 10,000)$ for loading controls.

\section{Dynamic insulin secretion}

The effects of acute exposure of mouse and human islets to increasing glucose concentrations ( $2 \mathrm{mM}$ $20 \mathrm{mM}$ ) on dynamic insulin secretion were assessed using a temperature-controlled perifusion system [15]. Briefly, groups of 40 mouse or 50 human islets were transferred to chambers containing $1 \mu \mathrm{m}$ poresize nylon filters and perifused at a flow rate of $0.5 \mathrm{ml} / \mathrm{min}$ at $37^{\circ} \mathrm{C}$ with a physiological salt solution [14] supplemented with 2, 3.5, 5, 7.5, 10 and 20mM glucose. In some experiments islets were pre-perifused for 20 minutes with buffer containing STF-31, a selective inhibitor of GLUT1, and this inhibitor was present for the duration of the experiments. Perifusates were collected at 2 minute intervals and secreted insulin was measured by radioimmunoassay [16].

\section{ATP measurements}

Isolated human or mouse islets were incubated for 2 hours in a physiological salt solution [14] containing $2 \mathrm{mM}$ glucose then groups of 5 human islets or 3 mouse islets were transferred into white walled 96-well plates. Islets were incubated for one hour at $37^{\circ} \mathrm{C}$ in the presence of $2-20 \mathrm{mM}$ glucose, lysed and ATP levels were determined by chemoluminescence using the 3D-Cell Titer-Glo ${ }^{\circ}$ assay, according to the manufacturer's instructions.

\section{Statistical analyses}

Numerical data are expressed as mean \pm SEM. The numbers of experiments and replicates are included in the figure legends. Statistical analyses were performed using Prism ${ }^{\circledR}$ GraphPad software. Differences were considered significant for $\mathrm{p}$ values $<0.05$.

\section{Results}

Differential expression of glucose transporters in human and mouse islets

The presence of the insulin-insensitive glucose transporters, GLUT1, GLUT2 and GLUT3, in mouse and human islets was evaluated both in terms of mRNA and protein expression. Real time gene expression analyses indicated that mRNA levels of Slc2a1 and Slc2a3, which encode GLUT1 and GLUT3, were very low in mouse islets, while Slc2a2 mRNA was approximately 
30-50-fold more abundant in mouse islets than the low $\mathrm{K}_{\mathrm{m}}$ transporters. In contrast, in human islets SLC2A1 was the most abundant mRNA of the three quantified, with lower levels of SLC2A3 and SLC2A2 mRNAs (Fig. 1a). Western blotting of fractionated islet lysates demonstrated that GLUT1 and GLUT3 proteins were readily detected in human islets, while GLUT2 expression was very low. Also consistent with the qPCR data, mouse islets had high expression of GLUT2, with lesser amounts of GLUTs 1 and 3 (Fig. 1b).

Human islets show a left-shifted insulin secretory response to glucose

Dynamic insulin secretory profiles of isolated human and mouse islets exposed to incremental increases in glucose concentration from $2 \mathrm{mM}$ to $20 \mathrm{mM}$ revealed that human islets have a left-shifted glucose concentration dependency compared to mouse islets (Fig. 2). Thus, human islets showed significantly elevated insulin release when the glucose concentration was increased from $2 \mathrm{mM}$ to $3.5 \mathrm{mM}$ and in the majority of experiments secretion was maximal at $7.5 \mathrm{mM}$ glucose, with no further increase at 10 or $20 \mathrm{mM}$ glucose (Fig. 2, solid squares). However, we found that in two of the nine batches of human islets analysed further increases in insulin secretion were obtained at 10 and $20 \mathrm{mM}$ glucose $(420 \pm 11 \%$ and $525 \pm 12 \%$ basal, respectively), indicating functional variations in islets from different donors. In contrast to the data obtained with human islets, the insulin secretory rate from mouse islets remained similar to the basal levels obtained at $2 \mathrm{mM}$ glucose until the concentration of glucose in the buffer was increased to $10 \mathrm{mM}$, and there was a further large increase in the secretory response from mouse islets at $20 \mathrm{mM}$ glucose (Fig. 2, open squares).

\section{ATP production correlates with changes in glucose concentration}

Glucose undergoes glycolytic metabolism in the cytoplasm following GLUTs-mediated entry into $\beta$-cells. The pyruvate that is generated enters the mitochondrial TCA cycle and drives mitochondrial ATP synthesis. Quantification of ATP generation in human islets indicated that glucose-dependent elevations in ATP followed a profile similar to that observed for glucose-induced insulin secretion. Thus, it can be seen from Fig. 3a that there was a significant elevation in ATP in human islets when glucose concentrations were increased from $2 \mathrm{mM}$ to $3.5 \mathrm{mM}$, with increasing glucose concentrations having very little additional effects on ATP levels. In contrast, parallel experiments with mouse islets revealed that there was not an increase in ATP production at $3.5 \mathrm{mM}$ glucose, but there were significant elevations at glucose concentrations of 5-20mM (Fig. 3b). Thus, it appears that the coupling between ATP 
generation and insulin secretion is more efficient in human islets than in mouse islets since the increases in ATP in the mouse islets at 5 and $7.5 \mathrm{mM}$ glucose were not associated with increased insulin secretion, as shown in Fig. 2. Nonetheless, at $20 \mathrm{mM}$ glucose there was a robust insulin secretory response in the mouse islets.

Selective inhibition of GLUT1 impairs glucosestimulated insulin secretion from human islets.

Since there was dif-

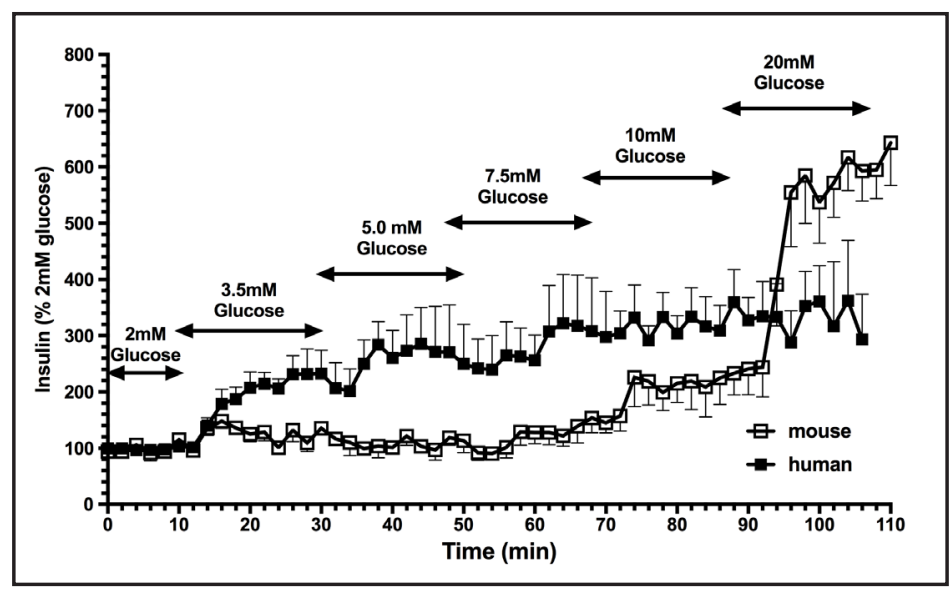

Fig. 2. Dynamic insulin secretion from human (solid squares) and mouse (open squares) islets challenged with increasing concentrations of glucose, as shown by the horizontal arrows. Data are expressed as mean \pm SEM of 4 independent replicates within individual experiments that are representative of data obtained with islets from 9 human donors and 3 mouse islet preparations.

ferential GLUT1 expression between human and mouse islets, which could account for the differential glucose responsiveness, the impact of the selective GLUT1 inhibitor STF-31 [17] on ATP production and insulin secretion was evaluated. Fig. 4a shows that inhibition of GLUT1 with STF-31 did not produce any changes in the secretory ability of mouse islets at glucose concentrations of $3.5-7.5 \mathrm{mM}$, with insulin output remaining at basal levels despite the increase in glucose concentration both in the absence and presence of STF-31. In contrast, glucose-induced insulin secretion from human islets was significantly impaired following STF-31-induced inhibition of GLUT1 activity (Fig. 4b) and STF-31 also significantly inhibited glucosestimulated ATP generation in human islets (Fig. 4c).

\section{Discussion}

Of the 14 GLUT family members so far identified, islet $\beta$-cells express mainly GLUT 1,2 and 3 isoforms of the Class I family [8-10]. These GLUTs are characterised by different affinities for glucose such that when glucose

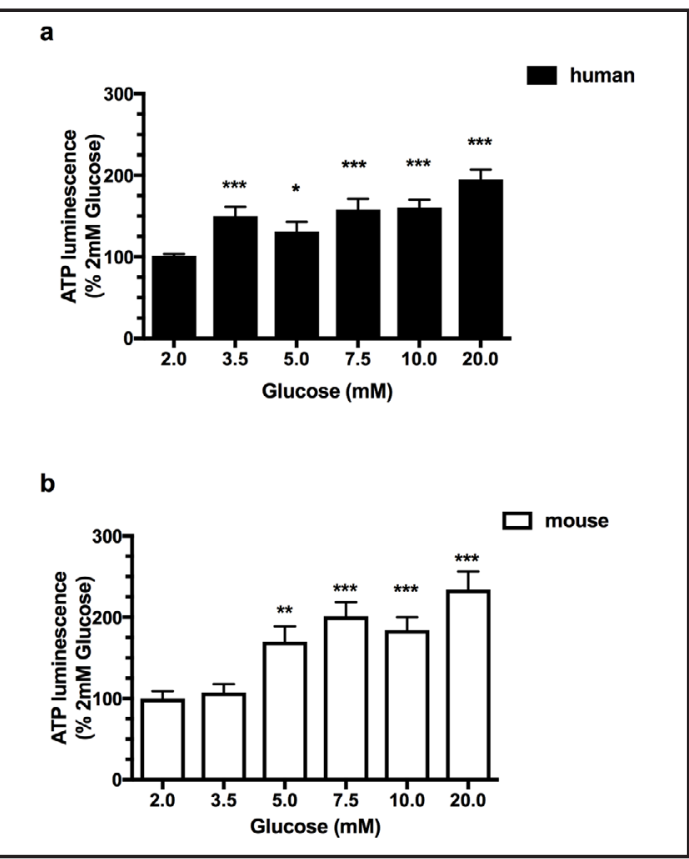

Fig. 3. Measurement of intracellular ATP levels in human (a) and mouse (b) islets. Data are expressed as mean+SEM of 6-10 replicates per group and they are representative of experiments with islets from 5 human donors and 2 separate batches of mouse islets. ${ }^{*} \mathrm{p}<0.05,{ }^{* *} \mathrm{p}<0.01$ and ${ }^{* * *} \mathrm{p}<0.001$ vs $2 \mathrm{mM}$ glucose. concentrations are low the high affinity, low $\mathrm{K}_{\mathrm{m}}$ GLUT1 and GLUT3 transporters are responsible for glucose entry into $\beta$-cells, while the very low affinity, high capacity GLUT2 is most active at higher glucose concentrations, allowing rapid equilibration of extra- and intracellular glucose. Rodent and human islets have many similarities in terms of gene 
expression and function [4, 8-10], but the glucose sensing apparatus shows species specificity, such that mice mainly express GLUT2 and the predominant isoforms in human islets are GLUT1/3, as shown in the current study by qPCR and western blotting. An earlier report of immunohistochemical staining of human pancreas indicated widespread expression of GLUT1 and GLUT3 in islets, consistent with $\beta$-cell localisation [8], and co-staining with insulin confirmed that these GLUTs are expressed by human $\beta$-cells [10]. This different pattern of expression between mouse and human $\beta$-cells should confer different glucose-sensing properties that reflect speciesspecific abilities to regulate glucose homeostasis in terms of both basal and post-prandial glycaemia.

Our profiling of dynamic insulin secretion from isolated human and mouse islets allows direct investigation of glucosedependent $\beta$-cell secretory function, independent of other variables that occur in vivo. Our data are in agreement with those generated earlier, of major expression of GLUT1 and GLUT3 rather than GLUT2 in human islets [8-10], and with the reported ability of human islets to secrete insulin at low glucose concentrations [18]. The catalytic activities of the glycolytic enzyme, glucokinase, are similar in mouse and human islets $[1,8]$, thus the left-shift in the glucose-induced insulin secretion profile from human islets that we have observed most likely reflects the differential expression of glucose transporters that allows glucose uptake into human islets at lower extracellular glucose concentrations. This preferential pattern of expression of GLUT1/3 in human islets and GLUT2 in mouse islets is consistent with circulating glucose concentrations being tightly regulated between $\sim 4-7 \mathrm{mM}$ in man [19] and $\sim 7-14 \mathrm{mM}$ in mouse [20].

Our data provide a direct functional link between the transporters responsible for glucose uptake and the capacity of $\beta$-cells to increase insulin secretion, particularly with respect to GLUT1. Thus, selective inhibition of this high affinity transporter with STF-31 significantly impaired both ATP generation and insulin secretion from human islets at 3.5, 5.0 and $7.5 \mathrm{mM}$ glucose, consistent with GLUT1 playing a pivotal role in uptake of physiological

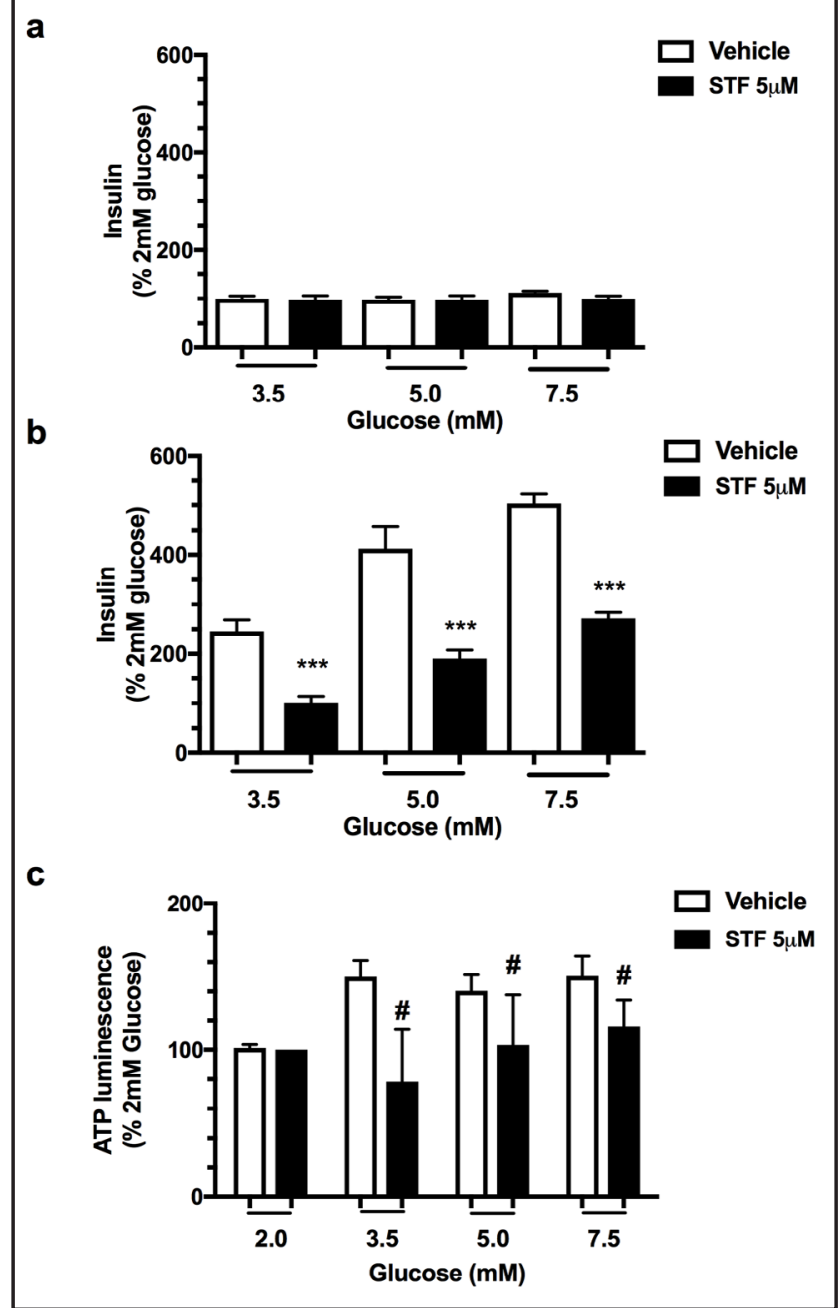

Fig. 4. Effect of GLUT1 inhibition on insulin secretion and ATP generation. Insulin secretion from isolated mouse (a) and human (b) islets, quantified after 20 minutes in the absence and presence of $5 \mu \mathrm{M}$ of the GLUT1 inhibitor STF-31 (STF). c) Intracellular ATP levels in human islets in the absence and presence of $5 \mu \mathrm{M}$ STF-31. Data are expressed as mean+SEM of 8-10 replicates per treatment group and they are representative of experiments with islets from 2 human donors and 2 separate batches of mouse islets. ${ }^{* * *}$ and $\# \mathrm{p}<0.001$ vs untreated (vehicle) control.

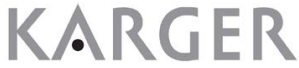


concentrations of glucose into human $\beta$-cells followed by its metabolism and induction of secretory granule exocytosis. Nonetheless, it is important to consider that phosphorylation of glucose by glucokinase is generally considered to be the rate-limiting step in glucoseinduced stimulus-response coupling in $\beta$-cells $[4,5]$, so inhibition of glucose transport capacity would not be expected to completely block glucose-stimulated insulin release. Furthermore, inhibition of GLUT1 should retard rather than prevent the equilibration between extracellular and intracellular glucose concentrations when glucose levels are raised, so even in the presence of a maximal inhibitory concentration of STF-31 [17] some glucose would be able to enter the human $\beta$-cells, either through incomplete inhibition of GLUT1, or through GLUT3, which has a similarly high affinity for glucose as GLUT1 and which is not inhibited by STF-1. It is unlikely that the low levels of GLUT2 expressed by human islets play an important role in glucose entry under physiological conditions, but this high $\mathrm{K}_{\mathrm{m}}$ transporter would be expected to permit enhanced entry of glucose under conditions of hyperglycaemia, such as might occur under conditions of glucose intolerance or diabetes. It has been suggested that glucose may trigger insulin secretion from human islets at concentrations lower than those required for mouse islets as a result of human $\beta$-cells having lower resting activity of $\mathrm{K}_{\mathrm{ATP}}$ channels [21], which are closed when intracellular ATP concentrations increase after glucose internalisation. Our observations that ATP generation was stimulated in mouse islets at concentrations of glucose as low as $5 \mathrm{mM}$ but that this was not accompanied by increased insulin secretion until glucose was increased to $10 \mathrm{mM}$ may point to the existence of a different "energetic threshold" for triggering granule release between mouse and human islets, perhaps as a consequence of the lower threshold for $\mathrm{K}_{\text {ATP }}$ channel closure in human $\beta$-cells [21].

In conclusion, the in vitro dynamic responsiveness of isolated human islets in the range of $3.5-7.5 \mathrm{mM}$ glucose is consistent with the circulating glucose concentrations in humans and the expression of low $\mathrm{K}_{\mathrm{m}}$ GLUT1/3 by human islets. In contrast, the right-shifted insulin secretion profile of mouse islets reflects the elevated basal and stimulated blood glucose concentrations in mice and islet expression of the high $\mathrm{K}_{\mathrm{m}}$ GLUT2 transporter. Inhibition of GLUT1 activity in human islets reduced, but did not abolish, glucose-induced ATP generation or insulin secretion, suggesting that both GLUT1 and GLUT3 are required for appropriate glucose transport in human islets. Our data indicate that while mouse islets represent a valid alternative to human islets, biochemical differences in metabolic coupling should be taken into account when considering whether observations made using mouse islets are directly translatable into a human context.

\section{Acknowledgements}

We are grateful to the families of the organ donors for making islets available for research. This work was funded by the Diabetes Research and Wellness Foundation through a Pump Priming Award to AP and SJP.

\section{Disclosure Statement}

The authors declare no competing financial interests.

\section{References}

1 Cabrera O, Berman DM, Kenyon NS, Ricordi C, Berggren PO, Caicedo A: The unique cytoarchitecture of human pancreatic islets has implications for islet cell function. Proc Natl Acad Sci U S A 2006;103:23342339. 


\section{Cellular Physiology Cell Physiol Biochem 2017;44:1352-1359 \begin{tabular}{l|l|l} 
and Biochemistry Published online: November 30, 2017 & $\begin{array}{l}\text { (c) } 2017 \text { The Author(s). Published by S. Karger AG, Basel } \\
\text { www.karger.com/cpb }\end{array}$
\end{tabular}}

Pingitore et al.: Human and Mouse Islet Glucose Sensitivity

-2 Amisten S, Atanes P, Hawkes R, Ruz-Maldonado I, Liu B, Parandeh F, Zhao M, Huang GC, Salehi A, Persaud SJ: A comparative analysis of human and mouse islet G-protein coupled receptor expression. Sci Rep 2017;7:46600 DOI: 10.1038/srep46600.

3 Persaud SJ, Liu B, Jones PM: Functional analysis of human islets of Langerhans maintained in culture; in: Mitry R, Hughes R (eds): Human Cell Culture, Methods in Molecular Biology, Humana Press 2012, pp 55-71.

- 4 Jones PM, Persaud SJ: Islet function and insulin secretion, in: Holt RIG, Cockram C, Flyvbjerg A, Goldstein BJ (eds): Textbook of Diabetes, 5th edition, Blackwell Scientific Press, UK 2017, pp 87-102.

$>5$ Lenzen S: A fresh view of glycolysis and glucokinase regulation: history and current status. J Biol Chem 2014;289:12189-12194.

-6 Ashcroft FM, Kakei M, Gibson JS, Gray DW, Sutton R: The ATP- and tolbutamide-sensitivity of the ATPsensitive K-channel from human pancreatic $\beta$-cells. Diabetologia 1989;32:591-598.

7 Davalli AM, Biancardi E, Pollo A, Socci C, Pontiroli AE, Pozza G, Clementi F, Sher E, Carbone E: Dihydropyridine-sensitive and -insensitive voltage-operated calcium channels participate in the control of glucose-induced insulin release from human pancreatic $\beta$ cells. J Endocrinol 1996;150:195-203.

-8 De Vos A, Heimberg H, Quartier E, Huypens P, Bouwens L, Pipeleers D, Schuit F: Human and rat beta cells differ in glucose transporter but not in glucokinase gene expression. J Clin Invest 1995;96:2489-2495.

-9 Ferrer J, Benito C, Gomis R: Pancreatic islet GLUT2 glucose transporter mRNA and protein expression in humans with and without NIDDM. Diabetes 1995;44:1369-1374.

10 McCulloch, Van de Bunt M, Braun M, Frayn KN, Clark A, Gloyn AL: GLUT2 (SLC2A2) is not the principal glucose transporter in human pancreatic beta cells: Implications for understanding genetic association signals at this locus. Mol Genetics Metab 2011;104:648-653.

-11 Mueckler M, Thorens B: The SLC2 (GLUT) family of membrane transporters. Mol Aspects Med 2013;34:121-138.

12 Huang GC, Zhao M, Jones P, Persaud S, Ramracheya R, Löbner K, Christie MR, Banga JP, Peakman M, Sirinivsan P, Rela M, Heaton N, Amiel S: The development of new density gradient media for purifying human islets and islet-quality assessments. Transplantation 2004;77:143-145.

-13 Papadimitriou A, King AJ, Jones PM, Persaud SJ: Anti-apoptotic effects of arachidonic acid and prostaglandin E2 in pancreatic beta-cells Cell Physiol Biochem 2007;20:607-616.

14 Gey GO, Gey MK: The maintenance of human normal cells and tumor cells in continuous culture. Am J Cancer 1936;27:45-76.

15 Pingitore A, Caroleo MC, Cione E, Castañera Gonzalez R, Huang GC, Persaud SJ: Fine tuning of insulin secretion by release of nerve growth factor from mouse and human islet $\beta$-cells. Mol Cell Endocrinol 2016;436:23-32.

-16 Jones PM, Salmon DM, Howell SL: Protein phosphorylation in electrically permeabilized islets of Langerhans. Effects of $\mathrm{Ca}^{2+}$, cyclic AMP, a phorbol ester and noradrenaline. Biochem J 1988;254:397-403.

17 Chan DA, Sutphin PD, Nguyen P, Turcotte S, Lai EW, Banh A, Reynolds GE, Chi JT, Wu J, Solow-Cordero DE, Bonnet M, Flanagan JU, Bouley DM, Graves EE, Denny WA, Hay MP, Giaccia AJ: Targeting GLUT1 and the Warburg effect in renal cell carcinoma by chemical synthetic lethality. Sci Transl Med 2011;3:94ra70 DOI: $10.1126 /$ scitranslmed.3002394.

-18 Henquin J, Dufrane D, Nenquin M: Nutrient control of insulin secretion in isolated normal human islets. Diabetes 2006;55:3470-3477.

19 Cryer PE: Regulation of glucose metabolism in man. J Intern Med Suppl 1991;735:31-39.

20 Togashi Y, Shirakawa J, Okuyama T, Yamazaki S, Kyohara M, Miyazawa A, Suzuki T, Hamada M, Terauchi Y: Evaluation of the appropriateness of using glucometers for measuring the blood glucose levels in mice. Sci Rep 2016;6:25465.

-21 Rorsman P, Braun M: Regulation of insulin secretion in human pancreatic islets. Ann Rev Physiol 2013;75:155-179. 